\title{
Proton Acceptor near the Active Site Lowers Dramatically the 0-O Bond Formation Energy Barrier in Photocatalytic Water Splitting
}

\author{
Yang Shao,*ㄹ Huub J.M. de Groot, ${ }^{(0)}$ and Francesco Buda*(i) \\ Leiden Institute of Chemistry, Leiden University, Einsteinweg 55, 2300 RA Leiden, The Netherlands \\ Supporting Information
}

\begin{abstract}
The $\mathrm{O}-\mathrm{O}$ bond formation process via water nucleophilic attack represents a thermodynamic and kinetic bottleneck in photocatalytic water oxidation because of the considerably high activation free energy barrier. It is therefore of fundamental significance and yet challenging to find strategies to facilitate this reaction. The microscopic details of the photocatalytic water oxidation step involving the $\mathrm{O}-\mathrm{O}$ bond formation in a catalyst-dye supramolecular complex are here elucidated by density functional theory-based Car-Parrinello molecular dynamics simulations in the presence of an extra proton acceptor. Introducing a proton acceptor group $\left(\mathrm{OH}^{-}\right)$in the hydration shell near the catalytic active site accelerates the rate-limiting $\mathrm{O}-\mathrm{O}$ bond formation by inducing a cooperative event proceeding via a concerted proton-coupled electron-transfer mechanism and thus significantly lowering the activation free energy barrier. The in-depth insight provides a strategy for facilitating the photocatalytic water oxidation and for improving the efficiency of dye-sensitized photoelectrochemical cells.
\end{abstract}

$\mathrm{D}$ irect conversion of solar energy into storable fuels, as a credible alternative of fossil fuels, has long been considered as an attractive approach to meet long-term sustainable energy needs. ${ }^{1-3}$ Dye-sensitized photoelectrochemical cells (DS-PECs) for solar-driven water splitting provide an opportunity to develop artificial photosynthetic devices by integrating visible light-absorbing sensitizers with water oxidation catalysts (WOCs) or hydrogen-evolving catalysts (HECs) on metal-oxide electrodes. ${ }^{4-8}$ In DS-PECs, water is oxidized to oxygens and protons by photogenerated holes at the (photo)anode whereas protons $/ \mathrm{CO}_{2}$ are reduced by photoinduced electrons at the (photo)cathode to produce energy-rich $\mathrm{H}_{2}$ or $\mathrm{CO}_{2}$-derived fuels. The process is thermodynamically driven by the photooxidation of sensitizers which should be coupled with WOCs/HECs and anchored to a metal-oxide semiconductor surface. ${ }^{9-13}$

Although increasing effort has been devoted to developing efficient dye-sensitized photoanodes, the photocatalytic fourphoton water oxidation half-reaction is still among the most crucial challenges throughout the entire process impeding the large-scale implementation of DS-PEC devices today. ${ }^{9,10}$ Among the four proton-coupled electron transfer $(\mathrm{PCET})^{14,15}$ steps involved in catalytic water oxidation, the $\mathrm{O}-\mathrm{O}$ bond formation process represents a thermodynamic and kinetic bottleneck because of the considerably high activation free energy barrier, which is especially found when using monometallic catalysts that proceed via a waternucleophilic attack mechanism. ${ }^{16-19}$ Therefore, better understanding of the mechanism of $\mathrm{O}-\mathrm{O}$ bond formation is currently a key issue that has attracted enormous interest in the past decades. $^{20-22}$ We recently explored in silico the whole photocatalytic water splitting cycle driven by a WOC-dye supramolecular complex $\left[(\mathrm{cy}) \mathrm{Ru}^{\mathrm{II}} \text { bpy }\left(\mathrm{H}_{2} \mathrm{O}\right)\right]^{2+}-\mathrm{NDI}(\mathrm{cy}=p$ - cymene, bpy $=2,2^{\prime}$-bipyridine, NDI $=2,6$-diethoxy-1,4,5,8diimide-naphthalene) ([Ru $\left.{ }^{\mathrm{II}}-\mathrm{OH}_{2}\right]^{2+}-\mathrm{NDI}$ for short) solvated in explicit water by using DFT-based Car-Parrinello molecular dynamics (DFT-MD) simulations. ${ }^{23,24}$

Specifically, the third catalytic water oxidation step involving the $\mathrm{O}-\mathrm{O}$ bond formation proceeded more likely via a sequential PCET mechanism (see red arrows in Scheme 1$)^{25}$ and exhibited an activation free energy barrier $\left(\Delta G^{*}\right)$ as high as $15.9 \mathrm{kcal} \mathrm{mol}^{-1}(\sim 0.69 \mathrm{eV})$. Using transition state theory, this energy barrier translates into a reaction rate $k=15.7 \mathrm{~s}^{-1} .24$ On this time scale charge recombination from the semiconductor surface to the photooxidized dye becomes very likely, thus reducing the quantum efficiency of the process. It is therefore of fundamental importance to find strategies that avoid high-energy intermediates in the sequential PCET process, which has been estimated to be substantially endothermic, $^{25-28}$ and thus facilitate the $\mathrm{O}-\mathrm{O}$ bond formation.

Although rate enhancement has been experimentally observed in catalytic water oxidation via ligand modification of WOCs ${ }^{29-34}$ as well as solvent environmental tuning, ${ }^{35-40}$ the intrinsic mechanism at the molecular level is hidden behind the ensemble measurements. Computational studies play an important role in exploring the catalytic reaction mechanism and predicting the free energy change between reactant and product. ${ }^{41-44}$ In particular, the catalytic water oxidation step involving the $\mathrm{O}-\mathrm{O}$ bond formation process by single-site $\mathrm{Ru}$ metal complexes has been found to be $3-5$ orders of

Received: October 2, 2019

Accepted: November 25, 2019

Published: November 25, 2019 
Scheme 1. Four PCET Steps between the Catalytic Intermediates $\left(I_{i}\right)$ from $I_{1}$ to $I_{0}$ for Water Oxidation ${ }^{a}$

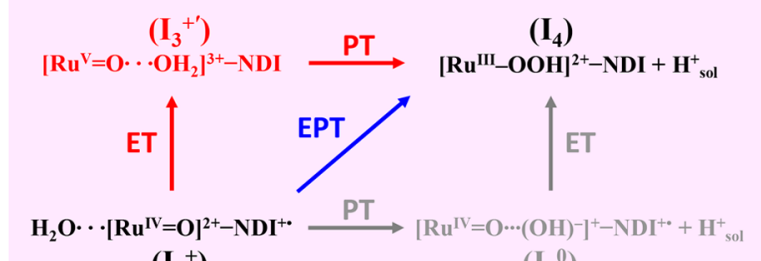

$\left(\mathrm{I}_{3}^{+}\right)$

$\left(\mathbf{I}_{3}{ }^{0}\right)$

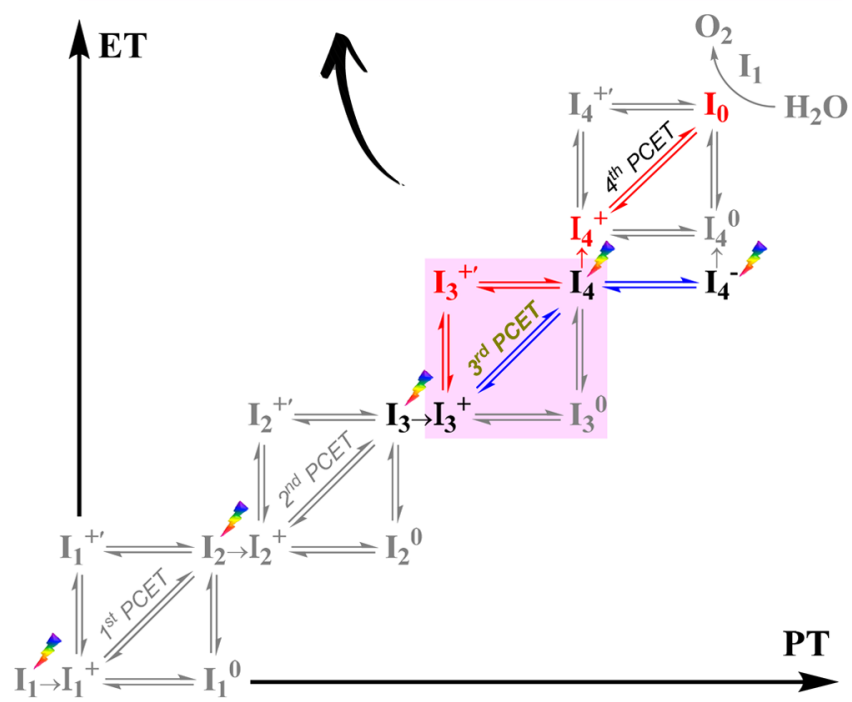

${ }^{a}$ It is assumed that each light flash induces the photooxidation of the NDI $\left(\mathrm{I}_{i} \rightarrow \mathrm{I}_{i}^{+}\right.$and $\left.\mathrm{I}_{4}^{-} \rightarrow \mathrm{I}_{4}{ }^{0}\right): \mathrm{NDI} \rightarrow \mathrm{NDI}^{+\bullet}$. The vertical and horizontal double arrows correspond to the pathways of sequential PCET mechanism, either electron transfer (ET) from the WOC to the oxidized dye first $\left(\mathrm{I}_{i}^{+} \rightarrow \mathrm{I}_{i}^{+1}, \mathrm{I}_{i}^{0} \rightarrow \mathrm{I}_{i+1}\right.$, and $\mathrm{I}_{4}{ }^{0} \rightarrow \mathrm{I}_{0}$ : WOC-dye ${ }^{+}$ $\rightarrow$ WOC $^{+}$-dye $)$or proton transfer $(\mathrm{PT})$ to the solvent first $\left(\mathrm{I}_{i}^{+} \rightarrow \mathrm{I}_{i}^{0}\right.$ and $\left.\mathrm{I}_{4} \rightarrow \mathrm{I}_{4}^{-}\right)$. The diagonal double arrow denotes the concerted mechanism labeled as EPT (concerted electron-proton transfer). The favorable pathway of the third catalytic step established in ref 24 is indicated in red, and the catalytic pathway in the presence of an $\mathrm{OH}^{-}$as a proton acceptor is in blue. Intermediates investigated in the present study are shown in black. The ligand exchange $\mathrm{I}_{0}+\mathrm{H}_{2} \mathrm{O} \rightarrow \mathrm{I}_{1}$ $+\mathrm{O}_{2}$ is also indicated. $\mathrm{H}^{+}$sol represents the proton transferred to the solvent. The third step from $\mathrm{I}_{3}^{+}$to $\mathrm{I}_{4}$, which is the main focus of this work, is specifically described in the top panel.

magnitude faster with the addition of buffer bases owing to their involvement in either concerted atom-proton transfer (APT) or concerted electron-proton transfer (EPT) pathways. $^{35,41,42}$ However, the thermodynamic and kinetic details of the mechanisms to accelerate the $\mathrm{O}-\mathrm{O}$ bond formation are still unaccounted for, especially when considering a visible-light sensitizer coupled to the WOC and a more explicit description of solvent effects.

Here we report how the introduction of an extra $\mathrm{OH}^{-}$group as proton acceptor in the hydration shell near the catalytic active site facilitates the $\mathrm{O}-\mathrm{O}$ bond formation process driven by the photooxidized dye in the $S=1 / 2$ supramolecular complex ${ }^{2}\left(\left[\mathrm{Ru}^{\mathrm{IV}}=\mathrm{O}\right]^{2+}-\mathrm{NDI}^{+\bullet}\right)($ see Scheme 2$)$.

To obtain a quantitative description of the $\mathrm{O}-\mathrm{O}$ bond formation process, we perform DFT-MD simulations using an orthorhombic box of dimensions $25.1 \times 17.7 \times 14.4 \AA^{3}$ with periodic boundary conditions $(\mathrm{pbc})$ containing the $[\mathrm{WOC}]^{2+}-$ dye solute, 161 water molecules, and one $\mathrm{OH}^{-}$group. In plane wave-based DFT-MD simulations with pbc, there is a spurious
Coulomb interaction for charged systems introduced by the image charges. However, because of the quite large simulation box used and the screening due to the explicit water molecules, the spurious effect of the periodic charges is estimated to be rather small (comparable to $k_{\mathrm{B}} T$ at room temperature) and does not affect significantly the conclusions of our simulations (see also Supporting Information S1). DFT-MD is an ideal approach to accurately describe chemical reactions in explicit solvent. $^{45}$ The solvent description allows more accurate predictions of the reaction mechanisms and activation free energy barriers, because the solvent directly participates in the reaction, as already emphasized in similar studies. ${ }^{46-49}$ All the simulations are performed at $300 \mathrm{~K}$ with the Car-Parrinello Molecular Dynamics (CPMD) program, ${ }^{50}$ using GTH pseudopotentials for the transition metal ${ }^{51}$ ruthenium and dispersion-corrected pseudopotentials (DCACP) for the remaining atoms, ${ }^{52}$ together with a plane wave cutoff of 70 $\mathrm{Ry}$ and the OPBE exchange-correlation functional ${ }^{53}$ (see Supporting Information section S1 for more computational details). Considering the restrictions in the time scale of DFT$\mathrm{MD}$ simulations, a constrained $\mathrm{MD}$ approach combined with thermodynamic integration was employed to compute the free energy profile along the $\mathrm{O}-\mathrm{O}$ bond formation process. ${ }^{54-56}$ The constrained reaction coordinate is the distance between the oxygen atoms $\mathrm{O}_{\mathrm{i}}$ and $\mathrm{O}_{\mathrm{ii}}$ indicated by the red double arrow in Scheme 2.

Inclusion and Equilibration of an $\mathrm{OH}^{-}$Ion in the Simulation Box. One water in the second solvation shell of the ruthenium center was deprotonated to create a hydroxide ion $\left(\mathrm{O}_{\mathrm{iii}} \mathrm{H}_{\mathrm{iii}}{ }^{-}\right)$in the system at the very beginning of the simulation (see Scheme 2). If the $\mathrm{OH}^{-}$ion is within $\sim 8 \AA$ of the $\mathrm{Ru}$ center, connected through a hydrogen bonded chain of water molecules, the $\mathrm{OH}^{-}$will move closer to the active site without any considerable energetic barrier by the Grotthuss mechanism. ${ }^{57}$ Therefore the exact initial position of the $\mathrm{OH}^{-}$is not so crucial and the mechanism will not change by placing the $\mathrm{OH}^{-}$in the second hydration shell of the attacking water molecule. The reaction coordinate $d\left(\mathrm{O}_{\mathrm{i}} \leftarrow \mathrm{O}_{\mathrm{ii}}\right)$ is initially fixed at $2.3 \AA$ near the transition state according to the recently estimated reaction mechanism of $\mathrm{O}-\mathrm{O}$ bond formation in a solvated system. ${ }^{24} \mathrm{An}$ initial DFT-MD simulation of about 1.5 ps is performed to equilibrate the local hydration environment around the $\mathrm{OH}^{-}$ group (see Supporting Information section S1.4 for more computational details). During this equilibration run, a strong hydrogen bond between the $\mathrm{OH}^{-}$group and the attacking water molecule is formed after about 0.8 ps with an average length $d\left(\mathrm{O}_{\mathrm{iii}} \cdots \mathrm{H}_{\mathrm{ii}}\right) \approx 1.9 \AA$ (see Figure 1a, black line). When the spin density is tracked, two unpaired $\alpha$ electrons are observed to localize on the catalyst and no unpaired electron on the NDI dye (see Figure 1a, inset), which is consistent with the ground state of the ${ }^{3}\left(\left[\mathrm{Ru}^{\mathrm{IV}}=\mathrm{O}\right]^{2+}-\mathrm{NDI}\right)$ intermediate known from previous investigations on this Ru-based catalyst. $^{24}$

The time-averaged $\mathrm{O}_{\mathrm{iii}}-\mathrm{O}$ radial distribution function $g_{\mathrm{O}_{\mathrm{iii}}-\mathrm{O}}(r)$ and the corresponding coordination number calculated in the equilibration simulation are presented in Figure $1 \mathrm{~b}$. The $g_{\mathrm{O}_{\mathrm{ii}}-\mathrm{O}}(r)$ function shows a deep minimum at the $\mathrm{O}_{\text {iii }}-\mathrm{O}$ distance $r \approx 2.9 \AA$, clearly revealing the existence of a first hydration shell of $\mathrm{OH}^{-} \cdot{ }^{58}$ Accordingly, the running coordination number $\left(n_{\mathrm{O}_{\mathrm{iii}}-\mathrm{O}}(2.9 \AA)\right)$ of the $\mathrm{OH}^{-}$group, defined as the number of water molecules with their oxygen atom within a radius of $2.9 \AA$ around the oxygen atom $\left(\mathrm{O}_{\mathrm{iii}}\right)$ of 
Scheme 2. Schematic Structure of ${ }^{2}\left(\left[(\mathrm{cy}) \mathrm{Ru}^{\mathrm{IV}} \mathrm{bpy}(\mathrm{O})\right]^{2+}-\mathrm{NDI}^{+\bullet}\right)$ Complex $\left({ }^{2}\left(\left[\mathrm{Ru}^{\mathrm{IV}}=\mathrm{O}\right]^{2+}-\mathrm{NDI}^{+\bullet}\right)\right.$ for short $) \mathrm{Used}$ in $\mathrm{This}^{\circ}$ Work Together with the Attacking Water Molecule and the $\mathrm{OH}^{-}$in the Vicinity of the Ru Center ${ }^{a}$

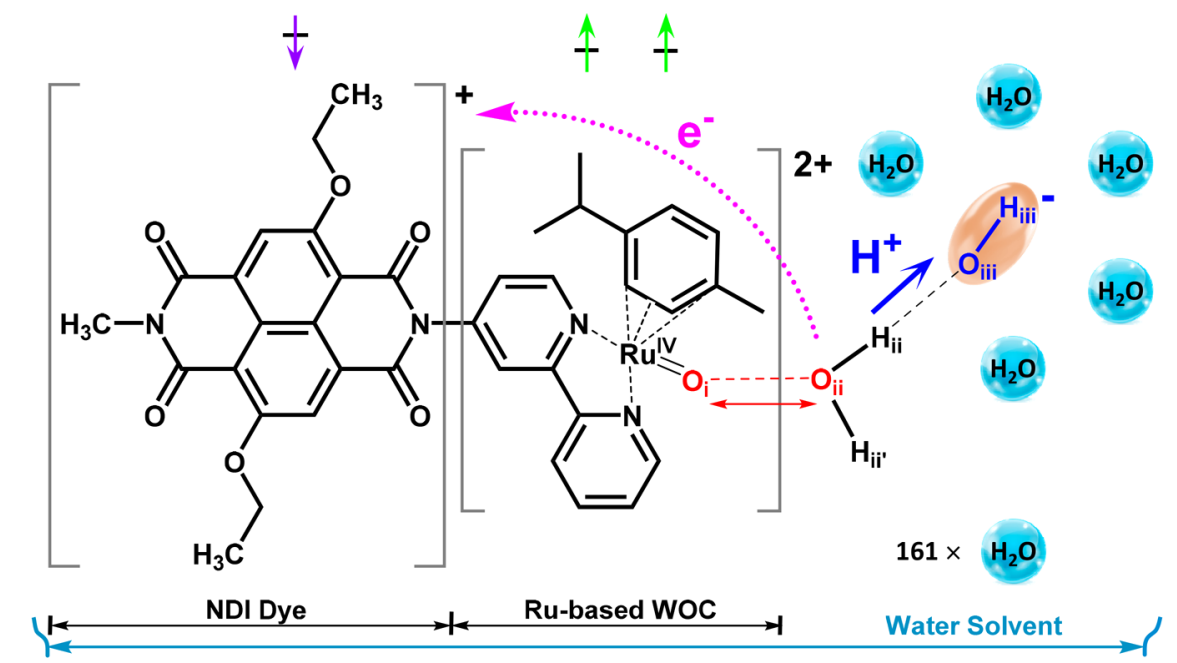

${ }^{a_{T}}$ The spin multiplicity value of 2 (total spin $S=1 / 2$ ) in this case corresponds to two unpaired $\alpha$ electrons (f) localized on the catalyst and one unpaired $\beta$ electron $(\downarrow)$ on the oxidized $\mathrm{NDI}^{+}$. The red double-sided arrow indicates the reaction coordinate used in the constrained $\mathrm{MD}$ simulations.

the $\mathrm{OH}^{-}$group, is shown in Figure 1c. The $\mathrm{OH}^{-}\left(\mathrm{H}_{2} \mathrm{O}\right)_{4}$ complex is observed to be the dominant solvation structure for $\mathrm{OH}^{-}$during this simulation, with four water molecules primarily coordinated to the $\mathrm{OH}^{-}$via hydrogen bonds (see Figure 1c, inset). This result is consistent with the coordination number obtained by integrating the first peak of the $g_{\mathrm{O}_{\mathrm{iii}} \mathrm{O}}(r)$ function (see Figure $1 \mathrm{~b}$, inset) and in agreement with the characteristic microscopic solvation structure of the $\mathrm{OH}^{-}$group in aqueous solution observed in previous simulations. ${ }^{58-64}$ All this evidence suggests a wellequilibrated solvation environment for the $\mathrm{OH}^{-}$that represents a good starting point for the subsequent reaction mechanism investigation.

Photooxidation of the NDI and $\mathrm{O}-\mathrm{O}$ Bond Formation. After this equilibration simulation, the photoinduced electron injection from the NDI to a $\mathrm{TiO}_{2}$ semiconductor surface, i.e., the photooxidation of the NDI dye, is mimicked by removing one electron from the simulation box. In previous work, we have demonstrated that the photoinduced electron injection is achieved in a time scale of $\sim 1$ ps. ${ }^{23}$ To obtain a quantitative description of electron and proton dynamics, the variation of the total spin density localized on the NDI dye and the time evolution of the distance between $\mathrm{Ru}$ and $\mathrm{OH}$ group (an $\mathrm{O}$ atom with only one $\mathrm{H}$ within a radius of $1.2 \AA$ ) along the constrained/free DFT-MD trajectory after photooxidation of NDI are collected in Figure 2. Initially, the photoinduced hole is localized on the oxidized $\mathrm{NDI}^{+}$(see Figure 2a,c), but it is quickly filled by an electron transferred from the attacking water molecule within $0.5 \mathrm{ps}$, leading to a minimum value around 0.1 of the spin density localized on NDI (see Figure 2a,e). Notice that during this electron transfer (ET) the total spin $S=1 / 2$ is conserved. At the same time, the attacking water molecule transfers a proton $\left(\mathrm{H}_{\mathrm{ii}}\right.$ in Scheme 2) to the $\mathrm{OH}^{-}$ion, which becomes a water molecule and no back reaction occurs (see Figure $2 \mathrm{~d}$ and blue line in panel $\mathrm{b}$ ). This result indicates a cooperative event proceeding via a concerted PCET mechanism (see EPT in Scheme 1) that is completed within $\sim 0.5$ ps after the photooxidation of the NDI (see Figure $2 \mathrm{a}-\mathrm{e})$.
In Figure 2e it is also apparent that the attacking water molecule has become an $\mathrm{OH}$ group carrying some spin density that indicates a strong radical character. One can indeed conclude that the hydroxide is first transferred close to the $\mathrm{Ru}(\mathrm{IV})=\mathrm{O}$; it acquires a radical character and thus generates a favorable condition for the $\mathrm{O}-\mathrm{O}$ bond formation. The configuration shown in Figure 2e would be observed if the $\mathrm{OH}^{-}$is placed initially as the direct attacking group next to the $\mathrm{Ru}(\mathrm{IV})=\mathrm{O}$. However, it is more appropriate to assume that the $\mathrm{OH}^{-}$group will approach the active site in its more stable solvated complex as described in Figure 1. After short-term fluctuations, the spin density localized on the NDI stabilizes to an average value around 0.1 in the second half of the constrained MD simulation, indicating almost complete ET from the attacking water molecule to the oxidized $\mathrm{NDI}^{+} \bullet$ (see Figure 2a).

This concerted PCET process occurs at the constrained reaction coordinate $d\left(\mathrm{O}_{\mathrm{i}} \leftarrow \mathrm{O}_{\mathrm{ii}}\right)=2.3 \AA$ in the presence of the $\mathrm{OH}^{-}$in the solvent. In contrast, without an additional proton acceptor the PCET occurs in a sequential (first ET, then PT; see red arrows in Scheme 1) mechanism and is completed only at $d\left(\mathrm{O}_{\mathrm{i}} \leftarrow \mathrm{O}_{\mathrm{ii}}\right)=1.8 \AA^{24}$

The release of the constraint between oxygens $\mathrm{O}_{\mathrm{i}}$ and $\mathrm{O}_{\mathrm{ii}}$ at $\sim 1.5$ ps enables the $\mathrm{O}-\mathrm{O}$ bond formation, which proceeds in a very short time (within $0.2 \mathrm{ps}$ ) as the bond distance equilibrates at an average value $d\left(\mathrm{O}_{\mathrm{i}}-\mathrm{O}_{\mathrm{ii}}\right)$ of $\sim 1.36 \AA$ (see red line in Figure 2b,f) (for comparison, the $\mathrm{O}-\mathrm{O}$ bond length in molecular hydrogen peroxide is $1.47 \AA$ ), confirming the accomplishment of the rate-limiting catalytic step (see eq 1 ). In eq $1, \mathrm{H}_{2} \mathrm{O}_{\text {sol }}$ and $\mathrm{OH}^{-}$sol represent the attacking water molecule and hydroxide ion in the solvent, respectively.

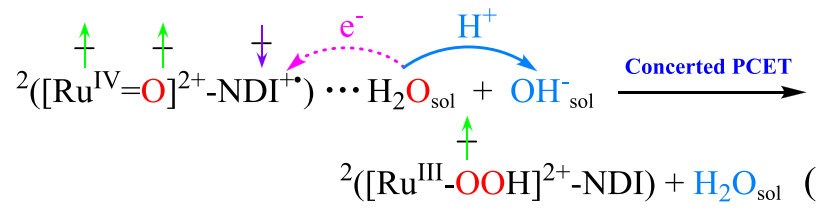



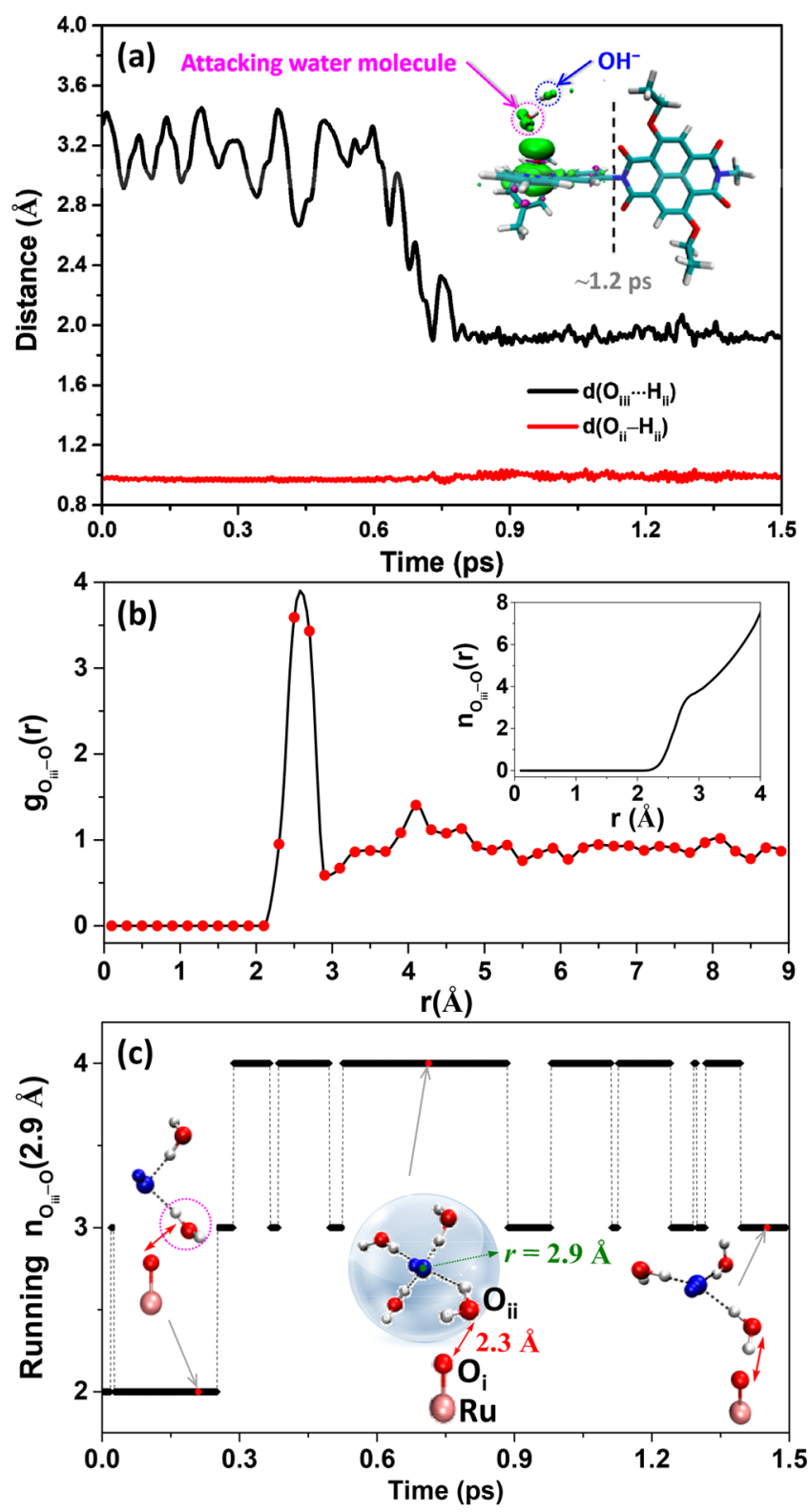

Figure 1. (a) Time evolution of the geometrical parameters $d\left(\mathrm{O}_{\mathrm{ii}}-\right.$ $\left.\mathrm{H}_{\mathrm{ii}}\right)$ (red line) and $d\left(\mathrm{O}_{\mathrm{iii}} \cdots \mathrm{H}_{\mathrm{ii}}\right)$ (black line) along the initial equilibration $\mathrm{MD}$ trajectory corresponding to the constraint value $d\left(\mathrm{O}_{\mathrm{i}} \leftarrow \mathrm{O}_{\mathrm{ii}}\right)=2.3 \AA$ (see Scheme 2 for the atomic labeling). The inset shows the spin density isosurface (green) computed at a snapshot taken at $\sim 1.2 \mathrm{ps}$, in the triplet state with two unpaired $\alpha$ electrons localized on the catalyst and no unpaired electron on the NDI dye. Only the ${ }^{3}\left(\left[\mathrm{Ru}^{\mathrm{IV}}=\mathrm{O}\right]^{2+}-\mathrm{NDI}\right)$ complex, attacking water molecule (magenta dashed circle), and $\mathrm{OH}^{-}$group (blue dashed circle) are shown explicitly. (b) Time-averaged $\mathrm{O}_{\mathrm{iii}}-\mathrm{O}$ radial distribution function and the corresponding integrated coordination number (inset in panel a) calculated for the $\mathrm{O}_{\text {iii }}$ of the $\mathrm{OH}^{-}$group in the equilibration simulation, in which the $\mathrm{O}$ labels the water atoms as opposite to the hydroxyl one. (c) Running coordination number of $\mathrm{OH}^{-}$along the equilibration MD trajectory. The insets in panel $\mathrm{c}$ show representative instantaneous snapshots for configurations with different coordination number, in which the $\mathrm{OH}^{-}$group is indicated in blue. Only the involved water molecules including the attacking water molecule (magenta dashed ellipse) hydrogen-bonded to the $\mathrm{OH}^{-}$group, the ruthenium metal center, and the oxo ligand coordinating to it are shown explicitly. The red double-sided arrow indicates the constrained distance $d\left(\mathrm{O}_{\mathrm{i}} \leftarrow \mathrm{O}_{\mathrm{ii}}\right)=2.3 \AA$.

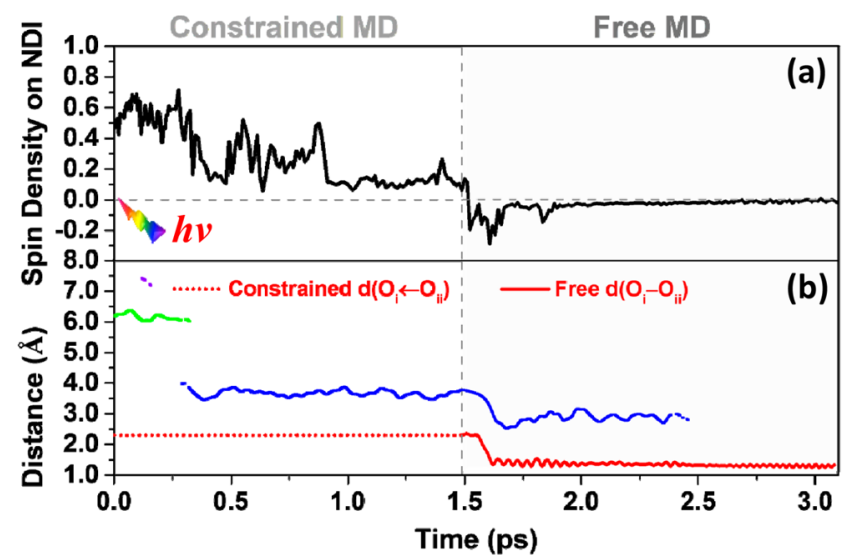

(c)
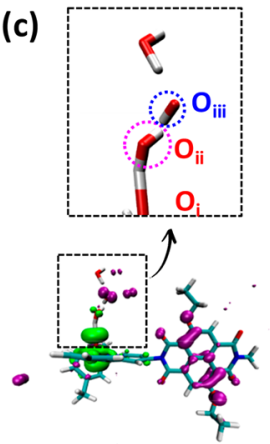

〜.1 ps (d)
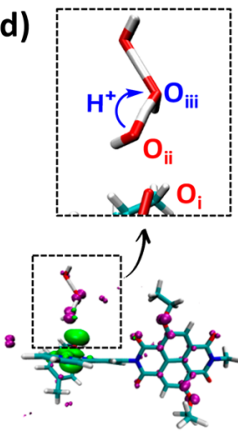

$\therefore \quad \sim 0.3 \mathrm{ps}$ (e)

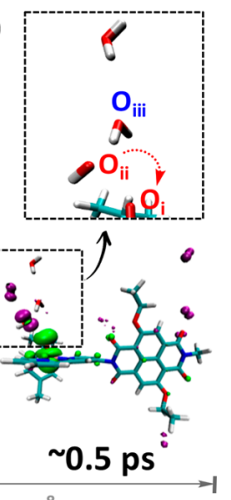

Constrained MD with $\mathrm{d}\left(\mathrm{O}_{\mathrm{i}} \leftarrow \mathrm{O}_{\mathrm{ii}}\right)=2.3 \AA$ (f)
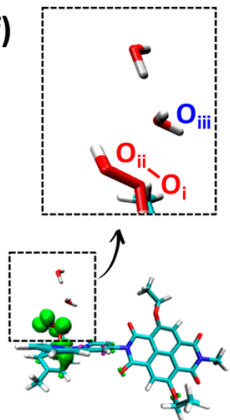

$\sim 1.8 \mathrm{ps}$ (g)
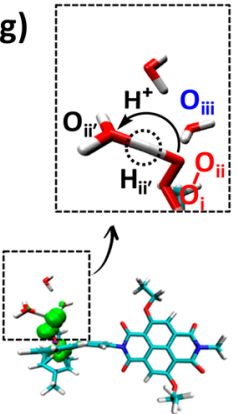

2.4 ps (h)
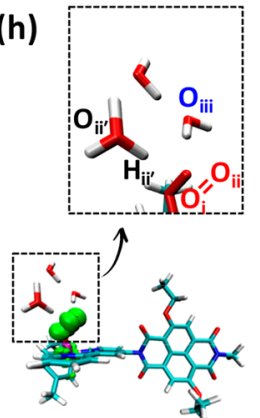

2.7 ps
Free MD

Figure 2. (a) Spin density integrated over the half of the simulation box that includes the NDI dye (right-hand side of the dashed black line in the inset of Figure 1a) along the constrained and free DFT$\mathrm{MD}$ trajectories with the presence of $\mathrm{OH}^{-}$group. An integrated spin density value of 1 corresponds to one unpaired $\beta$ electron ( $\downarrow$ ). (b) $d\left(\mathrm{O}_{\mathrm{i}}-\mathrm{O}_{\mathrm{ii}}\right)$ distance during the constrained (red dotted line) and free (red solid line) MD trajectories. The green, purple, and blue lines show the instantaneous distance between the $\mathrm{Ru}$ and the $\mathrm{OH}$ group defined as an $\mathrm{O}$ atom with only one $\mathrm{H}$ atom within a radius of $1.2 \AA$. Different colors are used to underline when the $\mathrm{OH}$ is transferred from one hydration shell to another. The $\mathrm{OH}$ is initially in the second hydration shell at about $6 \AA$ from the $\mathrm{Ru}$ (green line). The purple dots in the upper left corner indicate transient events in which a proton is accepted by a water molecule in the third hydration shell. Thus, the $\mathrm{OH}^{-}$moves temporarily further from the Ru complex and quickly jumps back in the second hydration shell. After about $0.3 \mathrm{ps}$, the proton is accepted from the attacking water, and thus, the $\mathrm{OH}$ moves closer to the $\mathrm{Ru}$ (blue line). ( $\mathrm{c}-\mathrm{h})$ Spin density localization at different snapshots together with PT of third catalytic step $(\mathrm{c} \rightarrow \mathrm{d} \rightarrow$ e), O-O bond formation process $(e \rightarrow f)$, and prior PT of fourth catalytic step $(\mathrm{g} \rightarrow \mathrm{h})$ along the constrained/free MD trajectory 
Figure 2. continued

shown in panels a and $b$. The labels refer to the time at which the snapshot has been taken. The snapshot taken at $\sim 0.1$ ps clearly indicates two unpaired $\alpha$ electrons (green spin density isosurface) localize on the catalyst and one unpaired $\beta$ electron (purple spin density isosurface) localizes on the oxidized $\mathrm{NDI}^{+}$dye. Only the WOC-dye complex, attacking water molecule (magenta dashed circle), $\mathrm{OH}^{-}$group (blue dashed circle), and one nearby water molecule are shown explicitly (see enlargement in the insets). A small amount of spin density can be seen localized on a few water molecules because of transient solvent polarization effects.

Spontaneous Proton Transfer Following OOH Ligand Formation. After the formation of the ${ }^{2}\left(\left[\mathrm{Ru}^{\mathrm{III}}-\mathrm{OOH}\right]^{2+}-\mathrm{NDI}\right)$ intermediate, the free DFT-MD simulation shows that the $\mathrm{H}_{\mathrm{ii}}$ of the hydroperoxyl ligand (see labeling in Scheme 2 and black dashed circle in Figure 2g) is strongly hydrogen-bonded to a neighboring water molecule. This hydrogen bond weakens the $\mathrm{O}_{\mathrm{ii}}-\mathrm{H}_{\mathrm{ii}}$ bond and facilitates the proton $\left(\mathrm{H}_{\mathrm{ii}}\right)$ release from the $\mathrm{Ru}^{\mathrm{III}}-\mathrm{OOH}$ center.

This proton is further transferred into the water bulk through a specific hydrogen-bonding network and finally forms a $\mathrm{H}_{5} \mathrm{O}_{2}{ }^{+}$complex in the solvent after $\sim 2.5 \mathrm{ps}$ during this simulation (see Figure $2 \mathrm{~h}$ and Supporting Information section $\mathrm{S} 2$ ). The last part of the free MD trajectory confirms the formation of an early $\mathrm{O}=\mathrm{O}$ bond with an average $d\left(\mathrm{O}_{\mathrm{i}}-\mathrm{O}_{\mathrm{ii}}\right)$ of $\sim 1.29 \AA$ (red line in Figure $2 \mathrm{~b}$; the $\mathrm{O}=\mathrm{O}$ bond length in molecular $\mathrm{O}_{2}$ is $1.21 \AA$ for comparison) and a weakened $\mathrm{Ru}-$ $\mathrm{O}_{\mathrm{i}}$ bond (see Figure S1a in the Supporting Information). One triplet molecular $\mathrm{O}_{2}$ can be produced and easily exchanged with a surrounding water molecule to generate the initial WOC state once the extra electron is transferred away from the $\mathrm{Ru}$ complex (see Scheme $1, \mathrm{I}_{4}{ }^{-} \rightarrow \mathrm{I}_{4}{ }^{0} \rightarrow \mathrm{I}_{0}$ ). These findings provide convincing evidence for a quite active intermediate with hydroperoxyl ligand after the $\mathrm{O}-\mathrm{O}$ bond formation process as well as a considerably thermodynamically facile fourth water oxidation step (see eq 2 , where $\mathrm{H}_{5} \mathrm{O}_{2}{ }^{+}$sol

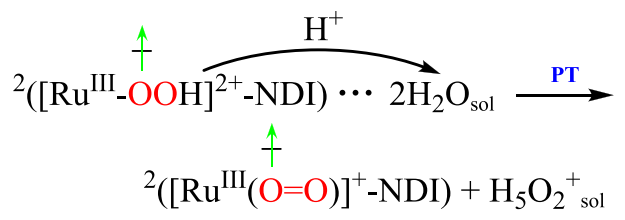

represents the hydrated excess proton complex). Interestingly, the barrier-less PT, usually considered as thermodynamically favorable after ET, ${ }^{65}$ proceeds spontaneously with no need for prior ET, emphasizing the possibility of rate enhancement in water oxidation catalysis by tuning solvent environment to allow prior or facilitated PT in the system. The analogy in the sequence of reaction steps predicted by the simulation after the photooxidation of the NDI (i.e., PCET followed by PT) and those observed in the oxygen-evolving complex of photosystem II after the third light flash leading to $\mathrm{O}_{2}$ evolution is noteworthy. ${ }^{2}$

Activation Free Energy Barrier and Reaction Rate Evaluation. Additional exploration with a constrained reaction coordinate $d\left(\mathrm{O}_{\mathrm{i}} \leftarrow \mathrm{O}_{\mathrm{ii}}\right)=2.5 \AA$ after the initial equilibration simulation discussed above is also carried out and reported for completeness in Supporting Information section S3. It is found that the PCET step could still take place when elongating the reaction coordinate $d\left(\mathrm{O}_{\mathrm{i}} \leftarrow \mathrm{O}_{\mathrm{ii}}\right)$ to $2.5 \AA$ with the presence of $\mathrm{OH}^{-}$as a proton acceptor in the solvent, although at a lower rate compared to the simulation with $d\left(\mathrm{O}_{\mathrm{i}}\right.$ $\leftarrow \mathrm{O}_{\mathrm{ii}}$ ) $=2.3 \AA$ (within 1.2 ps after the photooxidation of NDI). However, rapid electron recombination is observed after the release of constraint, which induces the migration of the attacking water molecule away from the $\mathrm{Ru}^{\mathrm{IV}}=\mathrm{O}_{i}$ center and the subsequent back reaction of transferred proton to reproduce the original attacking water molecule (see Figure S2).

In order to quantify the significant role of $\mathrm{OH}^{-}$as a proton acceptor in the solvent in facilitating the rate-limiting water oxidation step involving the $\mathrm{O}-\mathrm{O}$ bond formation process, the reaction coordinate $d\left(\mathrm{O}_{\mathrm{i}} \leftarrow \mathrm{O}_{\mathrm{ii}}\right)$ is constrained to a series of fixed values to estimate the free energy profile along this reaction pathway (see Supporting Information section S1.3 for more details). Figures $3 a$ (blue triangles) and $3 b$ (blue line)

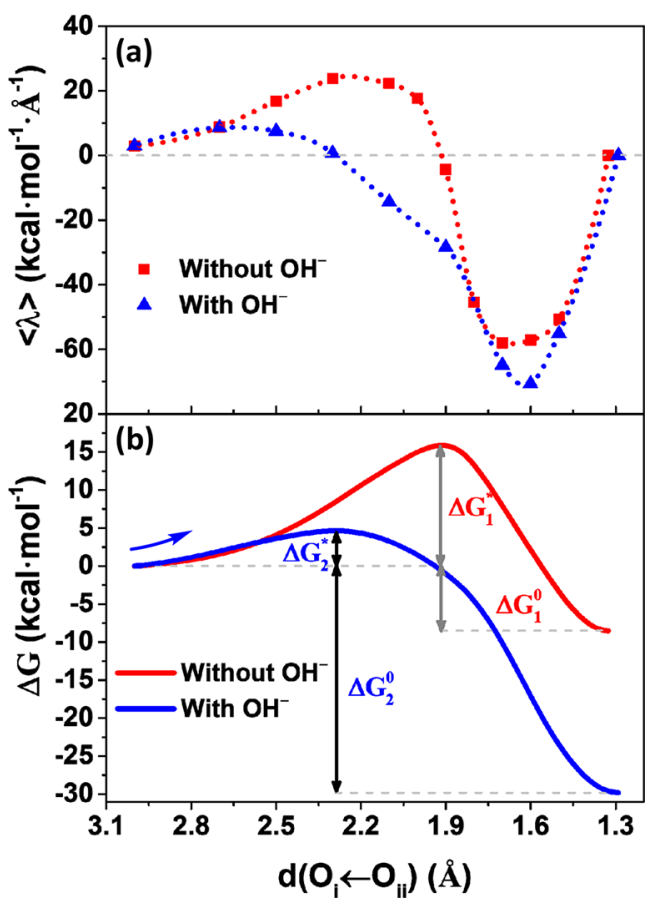

Figure 3. (a) Time-averaged constraint force represented by the Lagrangian multiplier $\langle\lambda\rangle$ computed for each constrained $\mathrm{MD}$ simulation as a function of the reaction coordinate $d\left(\mathrm{O}_{\mathrm{i}} \leftarrow \mathrm{O}_{\mathrm{ii}}\right)$ with (blue triangles) and without (red squares) the $\mathrm{OH}^{-}$. The Akima splines ( 100 points) is used to interpolate the mean forces. The mean force at the equilibrium distance $d\left(\mathrm{O}_{\mathrm{i}}-\mathrm{O}_{\mathrm{ii}}\right)=1.29 \AA$ evaluated in the free $\mathrm{MD}$ has been set to 0 . (b) Free energy profile along the reaction coordinate $d\left(\mathrm{O}_{\mathrm{i}} \leftarrow \mathrm{O}_{\mathrm{ii}}\right)$ computed by thermodynamic integration with (blue line) and without (red line) the $\mathrm{OH}^{-}$, respectively. The results obtained without the presence of $\mathrm{OH}^{-}$in the solvent are from ref 24 .

present the time-averaged mean forces corresponding to the applied constraint and associated free energy profile estimated by thermodynamic integration, respectively. The value of $\langle\lambda\rangle_{2.3 \AA} \approx 0$ observed in Figure $3 \mathrm{a}$ indicates a transition state of this reaction with a $\mathrm{O} \cdots \mathrm{O}$ distance close to $2.3 \AA$, which well explains why the $\mathrm{O}-\mathrm{O}$ bond formation cannot occur at $d\left(\mathrm{O}_{\mathrm{i}}\right.$ $\left.\leftarrow \mathrm{O}_{\mathrm{ii}}\right)=2.5 \AA$. In Table 1 , we summarize the thermodynamic parameters for this PCET step involving the $\mathrm{O}-\mathrm{O}$ bond formation with and without $\mathrm{OH}^{-}$. Noticeably, the calculated activation free energy barrier $\Delta G^{*}$ of this $\mathrm{O}-\mathrm{O}$ bond formation process is dramatically lowered to $\sim 4.3 \mathrm{kcal} \mathrm{mol}^{-1}$ 
Table 1. Calculated Activation Free Energy Barrier $\left(\Delta G^{*}\right.$, $\left.\mathrm{kcal} \mathrm{mol}^{-1}\right)$ and Reaction Driving Force $\left(\Delta G^{0}, \mathrm{kcal} \mathrm{mol}^{-1}\right)$ with and without $\mathrm{OH}^{-}$Group as a Proton Acceptor ${ }^{a}$

\begin{tabular}{lrrc}
\multicolumn{1}{c}{ water solvent } & $\Delta G^{*}$ & $\Delta G^{0}$ & $k_{2} / k_{1}$ \\
without $\mathrm{OH}^{-24}$ & 15.9 & -8.5 & $\sim 2.83 \times 10^{8}$ \\
with $\mathrm{OH}^{-}$ & 4.3 & -30.1 &
\end{tabular}

${ }^{a^{a}}$ The last column shows the rate ratio $\left(k_{2} / k_{1}\right)$ between the cases with $\left(k_{2}\right.$ in $\left.\mathrm{s}^{-1}\right)$ and without $\left(k_{1}\right.$ in $\left.\mathrm{s}^{-1}\right)$ the $\mathrm{OH}^{-}$group.

$(\sim 0.19 \mathrm{eV})$ compared to the case without the presence of $\mathrm{OH}^{-}$in the solvent $\left(\Delta G^{*} \approx 15.9 \mathrm{kcal} \mathrm{mol}^{-1}(\sim 0.69 \mathrm{eV})\right) .^{24}$

This reaction step turns out to be significantly facilitated by introducing $\mathrm{OH}^{-}$as proton acceptor near the active site to induce a concerted PCET mechanism. Moreover, the considerably larger driving force $\Delta G^{0} \approx-30.1 \mathrm{kcal} \mathrm{mol}^{-1}$ $(\sim 1.31 \mathrm{eV})$ found with the $\mathrm{OH}^{-}$can be partly attributed to the accomplishment of the spontaneous PT process after the formation of the hydroperoxyl ligand, which leads to a relatively more stable intermediate ${ }^{2}\left(\left[\mathrm{Ru}^{\mathrm{III}}(\mathrm{O}=\mathrm{O})\right]^{+}-\mathrm{NDI}\right)$ rather than ${ }^{2}\left(\left[\mathrm{Ru}^{\mathrm{III}}-\mathrm{OOH}\right]^{2+}-\mathrm{NDI}\right)$.

The computed activation free energy barrier can be used to evaluate to what extent the introduction of $\mathrm{OH}^{-}$group as a proton acceptor near the active site accelerates the rate of the $\mathrm{O}-\mathrm{O}$ bond formation. According to standard transition state theory, ${ }^{6-68}$ the reaction rate $(k)$ can be expressed as

$$
k=A \mathrm{e}^{-\Delta \mathrm{G}^{*} / R T}
$$

where $A$ is the preexponential frequency factor; $\Delta G^{*}$ represents the activation free energy barrier, and $R$ and $T$ are the universal gas constant and thermodynamic temperature, respectively. One should keep in mind that in the DFT-MD simulations protons are treated classically, and thus, proton tunneling effects are neglected. In the current estimate, only the activation free energy barrier is considered as a main factor governing the reaction rate and the preexponential factor is regarded as constant. The calculated ratio of reactions rate $\left(k_{2} /\right.$ $\left.k_{1} \approx 2.83 \times 10^{8}\right)$ indicates an increase of over 8 orders of magnitude for the $\mathrm{O}-\mathrm{O}$ bond formation process in the presence of a $\mathrm{OH}^{-}$as a proton acceptor near the active site (see Table 1), which is comparable with the experimental rate accelerations achieved by adding proton acceptor bases in the solution. $^{35,42}$

In conclusion, the explicit solvent and dynamic description obtained with the adiabatic DFT-MD modeling approach reveals that the photooxidation of the NDI dye covalently bound to a highly active mononuclear Ru-based WOC provides a sufficient driving force for the ET from the attacking water molecule to the oxidized $\mathrm{NDI}^{+} \bullet$ dye and thus drives this photocatalytic water oxidation step. Introducing one $\mathrm{OH}^{-}$group as a proton acceptor near the active site induces a cooperative event proceeding via a concerted PCET mechanism, dramatically lowers the activation free energy barrier, and thus significantly accelerates the $\mathrm{O}-\mathrm{O}$ bond formation.

The mechanistic insight into facilitated $\mathrm{O}-\mathrm{O}$ bond formation process provides a strategy for the improvement of the performance of DS-PEC devices by tuning the environment rather than developing novel catalysts for efficient water catalysis via tedious and costly synthesis technology. In this work we specifically use the $\mathrm{OH}^{-}$group as a conceptual example, but this can be easily replaced by other proton acceptors that would be less detrimental to the WOC stability.
On the basis of these results, we propose a design strategy for a DS-PEC architecture in which the catalyst layer is located in the proximity of an ion-exchange membrane. In particular, one could use assembly strategies similar to a solid-state water electrolysis cell with alkaline membranes in which the $\mathrm{OH}^{-}$ ions are transported to the catalyst layer through the anion exchange membrane and act as proton-withdrawing groups. ${ }^{69}$

Moreover, the decoupling of tuning of the proton chemical potential from tuning the electron chemical potential would be essential to the design of future optimal DS-PEC devices. This will facilitate the photocatalytic water oxidation and simultaneously the proton diffusion through the membrane for the purpose of efficient hydrogen production. ${ }^{70}$

\section{ASSOCIATED CONTENT}

\section{Supporting Information}

The Supporting Information is available free of charge at https://pubs.acs.org/doi/10.1021/acs.jpclett.9b02914.

Computational details, spontaneous prior PT process of the fourth catalytic water oxidation step after the $\mathrm{O}-\mathrm{O}$ bond formation, spin density distribution and geometrical parameters along the constrained $\left(d\left(\mathrm{O}_{\mathrm{i}} \leftarrow \mathrm{O}_{\mathrm{ii}}\right)\right.$ $=2.5 \AA$ ) $/$ free $\mathrm{MD}$ simulation (PDF)

\section{AUTHOR INFORMATION}

\section{Corresponding Authors}

*E-mail: f.buda@chem.leidenuniv.nl.

*E-mail: y.shao@lic.leidenuniv.nl.

ORCID

Yang Shao: 0000-0002-8606-7470

Huub J.M. de Groot: 0000-0002-8796-1212

Francesco Buda: 0000-0002-7157-7654

\section{Notes}

The authors declare no competing financial interest.

\section{ACKNOWLEDGMENTS}

We acknowledge the use of supercomputer facilities at SURFsara sponsored by NWO Physical Sciences, with financial support from The Netherlands Organization for Scientific Research (NWO). This research is supported by the NWO Solar to Products program, project number 733.000.007. Y.S. acknowledges financial support from the China Scholarship Council (No. 201606450019).

\section{REFERENCES}

(1) Lewis, N. S. Toward Cost-Effective Solar Energy Use. Science 2007, 315, 798-801.

(2) Dau, H.; Zaharieva, I. Principles, Efficiency, and Blueprint Character of Solar-Energy Conversion in Photosynthetic Water Oxidation. Acc. Chem. Res. 2009, 42, 1861-1870.

(3) Nocera, D. G. The Artificial Leaf. Acc. Chem. Res. 2012, 45, 767776.

(4) Li, L.; Duan, L.; Wen, F.; Li, C.; Wang, M.; Hagfeldt, A.; Sun, L. Visible light driven hydrogen production from a photo-active cathode based on a molecular catalyst and organic dye-sensitized p-type nanostructured NiO. Chem. Commun. 2012, 48, 988-990.

(5) Grätzel, M. Photoelectrochemical cells. Nature 2001, 414, 338344.

(6) Kohl, S. W.; Weiner, L.; Schwartsburd, L.; Konstantinovski, L.; Shimon, L. J. W.; Ben-David, Y.; Iron, M. A.; Milstein, D. Consecutive Thermal $\mathrm{H}_{2}$ and Light-Induced $\mathrm{O}_{2}$ Evolution from Water Promoted by a Metal Complex. Science 2009, 324, 74-77. 
(7) Xu, P.; Huang, T.; Huang, J.; Yan, Y.; Mallouk, T. E. Dyesensitized photoelectrochemical water oxidation through a buried junction. Proc. Natl. Acad. Sci. U. S. A. 2018, 115, 6946-6951.

(8) Yu, Z.; Li, F.; Sun, L. Recent advances in dye-sensitized photoelectrochemical cells for solar hydrogen production based on molecular components. Energy Environ. Sci. 2015, 8, 760-775.

(9) Swierk, J. R.; Mallouk, T. E. Design and development of photoanodes for water-splitting dye-sensitized photoelectrochemical cells. Chem. Soc. Rev. 2013, 42, 2357-2387.

(10) Ding, X.; Zhang, L.; Wang, Y.; Liu, A.; Gao, Y. Design of photoanode-based dye-sensitized photoelectrochemical cells assembling with transition metal complexes for visible light-induced water splitting. Coord. Chem. Rev. 2018, 357, 130-143.

(11) Gibson, E. A. Dye-sensitized photocathodes for $\mathrm{H} 2$ evolution. Chem. Soc. Rev. 2017, 46, 6194-6209.

(12) Xu, P.; McCool, N. S.; Mallouk, T. E. Water splitting dyesensitized solar cells. Nano Today 2017, 14, 42-58.

(13) Wang, D.; Eberhart, M. S.; Sheridan, M. V.; Hu, K.; Sherman, B. D.; Nayak, A.; Wang, Y.; Marquard, S. L.; Dares, C. J.; Meyer, T. J. Stabilized photoanodes for water oxidation by integration of organic dyes, water oxidation catalysts, and electron-transfer mediators. Proc. Natl. Acad. Sci. U. S. A. 2018, 115, 8523-8528.

(14) Gagliardi, C. J.; Vannucci, A. K.; Concepcion, J. J.; Chen, Z.; Meyer, T. J. The role of proton coupled electron transfer in water oxidation. Energy Environ. Sci. 2012, 5, 7704-7717.

(15) Hammes-Schiffer, S. Introduction: Proton-Coupled Electron Transfer. Chem. Rev. 2010, 110, 6937-6938.

(16) Yang, X.; Hall, M. B. Mechanism of Water Splitting and Oxygen-Oxygen Bond Formation by a Mononuclear Ruthenium Complex. J. Am. Chem. Soc. 2010, 132, 120-130.

(17) Concepcion, J. J.; Tsai, M.-K.; Muckerman, J. T.; Meyer, T. J. Mechanism of Water Oxidation by Single-Site Ruthenium Complex Catalysts. J. Am. Chem. Soc. 2010, 132, 1545-1557.

(18) Privalov, T.; Sun, L.; Åkermark, B.; Liu, J.; Gao, Y.; Wang, M. A Computational Study of O-O Bond Formation Catalyzed by Monoand Bis-MnIV-Corrole Complexes. Inorg. Chem. 2007, 46, 70757086

(19) Lin, X.; Hu, X.; Concepcion, J. J.; Chen, Z.; Liu, S.; Meyer, T. J.; Yang, W. Theoretical study of catalytic mechanism for single-site water oxidation process. Proc. Natl. Acad. Sci. U. S. A. 2012, 109, $15669-15672$

(20) Cao, R.; Lai, W.; Du, P. Catalytic water oxidation at single metal sites. Energy Environ. Sci. 2012, 5, 8134-8157.

(21) Shaffer, D. W.; Xie, Y.; Szalda, D. J.; Concepcion, J. J. Lability and Basicity of Bipyridine-Carboxylate-Phosphonate Ligand Accelerate Single-Site Water Oxidation by Ruthenium-Based Molecular Catalysts. J. Am. Chem. Soc. 2017, 139, 15347-15355.

(22) Meyer, T. J.; Sheridan, M. V.; Sherman, B. D. Mechanisms of molecular water oxidation in solution and on oxide surfaces. Chem. Soc. Rev. 2017, 46, 6148-6169.

(23) Monti, A.; de Ruiter, J. M.; de Groot, H. J. M.; Buda, F. A Dynamic View of Proton-Coupled Electron Transfer in Photocatalytic Water Splitting. J. Phys. Chem. C 2016, 120, 23074-23082.

(24) Shao, Y.; de Ruiter, J. M.; de Groot, H. J. M.; Buda, F. Photocatalytic Water Splitting Cycle in a Dye-Catalyst Supramolecular Complex: Ab Initio Molecular Dynamics Simulations. J. Phys. Chem. C 2019, 123, 21403-21414.

(25) Hammes-Schiffer, S. Proton-Coupled Electron Transfer: Moving Together and Charging Forward. J. Am. Chem. Soc. 2015, 137, 8860-8871.

(26) Iordanova, N.; Hammes-Schiffer, S. Theoretical Investigation of Large Kinetic Isotope Effects for Proton-Coupled Electron Transfer in Ruthenium Polypyridyl Complexes. J. Am. Chem. Soc. 2002, 124, 4848-4856.

(27) Hatcher, E.; Soudackov, A. V.; Hammes-Schiffer, S. ProtonCoupled Electron Transfer in Soybean Lipoxygenase. J. Am. Chem. Soc. 2004, 126, 5763-5775.

(28) Horvath, S.; Fernandez, L. E.; Soudackov, A. V.; HammesSchiffer, S. Insights into proton-coupled electron transfer mechanisms of electrocatalytic $\mathrm{H}_{2}$ oxidation and production. Proc. Natl. Acad. Sci. U. S. A. 2012, 109, 15663-15668.

(29) Maji, S.; Vigara, L.; Cottone, F.; Bozoglian, F.; Benet-Buchholz, J.; Llobet, A. Ligand Geometry Directs O-O Bond-Formation Pathway in Ruthenium-Based Water Oxidation Catalyst. Angew. Chem., Int. Ed. 2012, 51, 5967-5970.

(30) Garrido-Barros, P.; Funes-Ardoiz, I.; Drouet, S.; BenetBuchholz, J.; Maseras, F.; Llobet, A. Redox Non-innocent Ligand Controls Water Oxidation Overpotential in a New Family of Mononuclear Cu-Based Efficient Catalysts. J. Am. Chem. Soc. 2015, 137, 6758-6761.

(31) Wilson, A. D.; Newell, R. H.; McNevin, M. J.; Muckerman, J. T.; Rakowski DuBois, M.; DuBois, D. L. Hydrogen Oxidation and Production Using Nickel-Based Molecular Catalysts with Positioned Proton Relays. J. Am. Chem. Soc. 2006, 128, 358-366.

(32) Helm, M. L.; Stewart, M. P.; Bullock, R. M.; DuBois, M. R.; DuBois, D. L. A Synthetic Nickel Electrocatalyst with a Turnover Frequency Above 100,000 s $\mathrm{s}^{-1}$ for $\mathrm{H}_{2}$ Production. Science 2011, 333, 863-866.

(33) Bediako, D. K.; Solis, B. H.; Dogutan, D. K.; Roubelakis, M. M.; Maher, A. G.; Lee, C. H.; Chambers, M. B.; Hammes-Schiffer, S.; Nocera, D. G. Role of pendant proton relays and proton-coupled electron transfer on the hydrogen evolution reaction by nickel hangman porphyrins. Proc. Natl. Acad. Sci. U. S. A. 2014, 111, 1500115006.

(34) Solis, B. H.; Maher, A. G.; Honda, T.; Powers, D. C.; Nocera, D. G.; Hammes-Schiffer, S. Theoretical Analysis of Cobalt Hangman Porphyrins: Ligand Dearomatization and Mechanistic Implications for Hydrogen Evolution. ACS Catal. 2014, 4, 4516-4526.

(35) Song, N.; Concepcion, J. J.; Binstead, R. A.; Rudd, J. A.; Vannucci, A. K.; Dares, C. J.; Coggins, M. K.; Meyer, T. J. Baseenhanced catalytic water oxidation by a carboxylate-bipyridine $\mathrm{Ru}$ (II) complex. Proc. Natl. Acad. Sci. U. S. A. 2015, 112, 4935-4940.

(36) Norris, M. R.; Concepcion, J. J.; Fang, Z.; Templeton, J. L.; Meyer, T. J. Low-Overpotential Water Oxidation by a Surface-Bound Ruthenium-Chromophore-Ruthenium-Catalyst Assembly. Angew. Chem., Int. Ed. 2013, 52, 13580-13583.

(37) Coggins, M. K.; Zhang, M.-T.; Chen, Z.; Song, N.; Meyer, T. J. Single-Site Copper(II) Water Oxidation Electrocatalysis: Rate Enhancements with $\mathrm{HPO}_{4}{ }^{2-}$ as a Proton Acceptor at $\mathrm{pH}$ 8. Angew. Chem., Int. Ed. 2014, 53, 12226-12230.

(38) Chen, Z.; Concepcion, J. J.; Song, N.; Meyer, T. J. Chlorideassisted catalytic water oxidation. Chem. Commun. 2014, 50, 80538056.

(39) Stewart, D. J.; Concepcion, J. J.; Brennaman, M. K.; Binstead, R. A.; Meyer, T. J. Accelerating slow excited state proton transfer. Proc. Natl. Acad. Sci. U. S. A. 2013, 110, 876-880.

(40) Vannucci, A. K.; Alibabaei, L.; Losego, M. D.; Concepcion, J. J.; Kalanyan, B.; Parsons, G. N.; Meyer, T. J. Crossing the divide between homogeneous and heterogeneous catalysis in water oxidation. Proc. Natl. Acad. Sci. U. S. A. 2013, 110, 20918-20922.

(41) Matheu, R.; Ertem, M. Z.; Benet-Buchholz, J.; Coronado, E.; Batista, V. S.; Sala, X.; Llobet, A. Intramolecular Proton Transfer Boosts Water Oxidation Catalyzed by a Ru Complex. J. Am. Chem. Soc. 2015, 137, 10786-10795.

(42) Chen, Z.; Concepcion, J. J.; Hu, X.; Yang, W.; Hoertz, P. G.; Meyer, T. J. Concerted $\mathrm{O}$ atom-proton transfer in the $\mathrm{O}-\mathrm{O}$ bond forming step in water oxidation. Proc. Natl. Acad. Sci. U. S. A. 2010, $107,7225-7229$.

(43) Xie, Y.; Shaffer, D. W.; Lewandowska-Andralojc, A.; Szalda, D. J.; Concepcion, J. J. Water Oxidation by Ruthenium Complexes Incorporating Multifunctional Bipyridyl Diphosphonate Ligands. Angew. Chem., Int. Ed. 2016, 55, 8067-8071.

(44) Govindarajan, N.; Tiwari, A.; Ensing, B.; Meijer, E. J. Impact of the Ligand Flexibility and Solvent on the O-O Bond Formation Step in a Highly Active Ruthenium Water Oxidation Catalyst. Inorg. Chem. 2018, 57, 13063-13066. 
(45) Marx, D.; Hutter, J. Ab initio molecular dynamics: basic theory and advanced methods; Cambridge University Press: Cambridge, U.K., 2009.

(46) Handgraaf, J.-W.; Meijer, E. J. Realistic Modeling of Ruthenium-Catalyzed Transfer Hydrogenation. J. Am. Chem. Soc. 2007, 129, 3099-3103.

(47) Ma, C.; Piccinin, S.; Fabris, S. Reaction Mechanisms of Water Splitting and $\mathrm{H}_{2}$ Evolution by a $\mathrm{Ru}(\mathrm{II})$-Pincer Complex Identified with Ab Initio Metadynamics Simulations. ACS Catal. 2012, 2, 15001506.

(48) Pavlova, A.; Meijer, E. J. Understanding the Role of Water in Aqueous Ruthenium-Catalyzed Transfer Hydrogenation of Ketones. ChemPhysChem 2012, 13, 3492-3496.

(49) Vallés-Pardo, J. L.; Guijt, M. C.; Iannuzzi, M.; Joya, K. S.; de Groot, H. J. M.; Buda, F. Ab Initio Molecular Dynamics Study of Water Oxidation Reaction Pathways in Mono-Ru Catalysts. ChemPhysChem 2012, 13, 140-146.

(50) CPMD; http://www.cpmd.org; Copyright IBM Corp., 19902019; Copyright MPI für Festkörperforschung Stuttgart, 1997-2001. (51) Hartwigsen, C.; Goedecker, S.; Hutter, J. Relativistic separable dual-space Gaussian pseudopotentials from $\mathrm{H}$ to Rn. Phys. Rev. B: Condens. Matter Mater. Phys. 1998, 58, 3641-3662.

(52) Lin, I. C.; Coutinho-Neto, M. D.; Felsenheimer, C.; von Lilienfeld, O. A.; Tavernelli, I.; Rothlisberger, U. Library of dispersion-corrected atom-centered potentials for generalized gradient approximation functionals: Elements $\mathrm{H}, \mathrm{C}, \mathrm{N}, \mathrm{O}, \mathrm{He}, \mathrm{Ne}, \mathrm{Ar}$, and $\mathrm{Kr}$. Phys. Rev. B: Condens. Matter Mater. Phys. 2007, 75, 205131.

(53) Swart, M.; Ehlers, A. W.; Lammertsma, K. Performance of the OPBE exchange-correlation functional. Mol. Phys. 2004, 102, 24672474.

(54) Ciccotti, G.; Ferrario, M. Blue Moon Approach to Rare Events. Mol. Simul. 2004, 30, 787-793.

(55) Ensing, B.; Meijer, E. J.; Blöchl, P. E.; Baerends, E. J. Solvation Effects on the $\mathrm{S}_{\mathrm{N}} 2$ Reaction between $\mathrm{CH} 3 \mathrm{Cl}$ and $\mathrm{Cl}$ - in Water. J. Phys. Chem. A 2001, 105, 3300-3310.

(56) Costanzo, F.; Della Valle, R. G. Car-Parrinello MD Simulations for the $\mathrm{Na}^{+}-$Phenylalanine Complex in Aqueous Solution. J. Phys. Chem. B 2008, 112, 12783-12789.

(57) de Ruiter, J. M. Explorations of water oxidation catalysis in explicit solvent. Ph.D. Thesis, Leiden University, October 2018.

(58) Lee, S. H.; Rasaiah, J. C. Local dynamics and structure of the solvated hydroxide ion in water. Mol. Simul. 2010, 36, 69-73.

(59) Crespo, Y.; Hassanali, A. Unveiling the Janus-Like Properties of $\mathrm{OH}^{-}$. J. Phys. Chem. Lett. 2015, 6, 272-278.

(60) Tuckerman, M.; Laasonen, K.; Sprik, M.; Parrinello, M. Ab initio molecular dynamics simulation of the solvation and transport of hydronium and hydroxyl ions in water. J. Chem. Phys. 1995, 103, $150-161$.

(61) Tuckerman, M.; Laasonen, K.; Sprik, M.; Parrinello, M. Ab Initio Molecular Dynamics Simulation of the Solvation and Transport of $\mathrm{H}_{3} \mathrm{O}^{+}$and $\mathrm{OH}^{-}$Ions in Water. J. Phys. Chem. 1995, 99, 57495752.

(62) Chen, B.; Ivanov, I.; Park, J. M.; Parrinello, M.; Klein, M. L. Solvation Structure and Mobility Mechanism of $\mathrm{OH}^{-}$: A CarParrinello Molecular Dynamics Investigation of Alkaline Solutions. J. Phys. Chem. B 2002, 106, 12006-12016.

(63) Botti, A.; Bruni, F.; Imberti, S.; Ricci, M. A.; Soper, A. K. Ions in water: The microscopic structure of concentrated $\mathrm{NaOH}$ solutions. J. Chem. Phys. 2004, 120, 10154-10162.

(64) Agmon, N.; Bakker, H. J.; Campen, R. K.; Henchman, R. H.; Pohl, P.; Roke, S.; Thämer, M.; Hassanali, A. Protons and Hydroxide Ions in Aqueous Systems. Chem. Rev. 2016, 116, 7642-7672.

(65) de Ruiter, J. M.; de Groot, H. J. M.; Buda, F. Energetic Effects of a Closed System Approach Including Explicit Proton and Electron Acceptors as Demonstrated by a Mononuclear Ruthenium Water Oxidation Catalyst. Chem CatChem 2018, 10, 4594-4601.

(66) Eyring, H. The Activated Complex in Chemical Reactions. J. Chem. Phys. 1935, 3, 107-115.
(67) Laidler, K. J.; King, M. C. Development of transition-state theory. J. Phys. Chem. 1983, 87, 2657-2664.

(68) Pollak, E.; Talkner, P. Reaction rate theory: What it was, where is it today, and where is it going? Chaos 2005, 15, 026116.

(69) Leng, Y.; Chen, G.; Mendoza, A. J.; Tighe, T. B.; Hickner, M. A.; Wang, C.-Y. Solid-State Water Electrolysis with an Alkaline Membrane. J. Am. Chem. Soc. 2012, 134, 9054-9057.

(70) Achtyl, J. L.; Unocic, R. R.; Xu, L.; Cai, Y.; Raju, M.; Zhang, W.; Sacci, R. L.; Vlassiouk, I. V.; Fulvio, P. F.; Ganesh, P.; et al. Aqueous proton transfer across single-layer graphene. Nat. Commun. 2015, 6, 6539. 